\title{
E. Wyndham Hulme's Classification of the Attributes of Books: On an Early Model of a Core Bibliographical Entity
}

\begin{abstract}
Modelling bibliographical entities is a prominent activity within knowledge organization today. Current models of bibliographic entities, such as Functional Requirements for Bibliographical Records (FRBR) and the Bibliographic Framework (BIBFRAME), take inspiration from data-modelling methods developed by computer scientists from the mid-1970s on. Thus, it would seem that the modelling of bibliographic entities is an activity of very recent vintage. However, it is possible to find examples of bibliographical models from earlier periods of knowledge organization. The purpose of this paper is to draw attention to one such model, outlined by the early $20^{\text {th }}$-century British classification theorist E. Wyndham Hulme in his essay on "Principles of Book Classification" (1911-1912). There, Hulme set forth a classification of various attributes by which books can conceivably be classified. These he first divided into accidental and inseparable attributes. Accidental attributes were subdivided into edition-level and copy-level attributes and inseparable attitudes, into physical and non-physical attributes. Comparison of Hulme's classification of attributes with those of FRBR and BIBFRAME 2.0 reveals that the different classes of attributes in Hulme's classification correspond to groups of attributes associated with different bibliographical entities in those models. These later models assume the existence of different bibliographic entities in an abstraction hierarchy among which attributes are distributed, whereas Hulme posited only a single entitythe book-, whose various aspects he clustered into different classes of attributes. Thus, Hulme's model offers an interesting alternative to current assumptions about how to conceptualize the relationship between attributes and entities in the bibliographical universe
\end{abstract}

\section{Introduction}

Over the last thirty years, modelling bibliographical entities and the relationships among them has become an area of great interest and activity among theorists of cataloging and, more generally, of knowledge organization (Petek 2004). Some of the models created, such as the Functional Requirements for Bibliographic Records (FRBR) (IFLA Study Group on the Functional Requirements for Bibliographic Records, 1998), have already materially influenced the development of current cataloging standards (Croissant 2012), while others, such as the Bibliographic Framework (BIBFRAME) (Library of Congress 2012; 2016), are likely to have profound impact upon cataloging in the future (McCallum 2016).

Most current models of bibliographic entities have their basis in data-modelling methods derived from the field of computer science and are of relatively recent vintage. FRBR, for example, is a conceptual model rooted in entity-relationship modelling (Coyle 2016, 76-78; IFLA Study Group on the Functional Requirements for Bibliographic Records, 9-10), an approach to database design first articulated in the mid-1970s (Chen 1976), while BIBFRAME is based on the Resource Description Framework (RDF) (McCallum 2016), a data model developed for the World Wide Web in the late 1990s (e.g., Lassila 1998, 31-34; Miller 1998; Mitchell 2013, 13) and considered today to be a fundamental element in the constitution of the Semantic Web (e.g., Stuart 2016, 28-30,39). Thus, at first glance, it would seem that the modelling of bibliographic entities has had a very short history indeed. If, by bibliographic modelling, one means the use of data-modelling techniques for the express purpose of creating a conceptual model of bibliographic entities, their attributes, 
and their relationships (cf. Svenonius 2000, 32), then, indeed, such a conclusion is justified. However, if one understands bibliographic modelling in a less restrictive sense as encompassing any principled attempt to enumerate the attributes of a (kind of) bibliographical entity and to assess their significance in relating that (kind of) entity to others, then one may well expect to encounter examples of bibliographical models from earlier phases of the history of knowledge organization, before bibliographic modelling came to be recognized as an activity. Adopting this second, broader definition of bibliographic modelling, I wish, in this paper, to draw attention to, and analyze, a classification of the attributes of books set forth the writings of one of the pioneers of modern classification theory, E. Wyndham Hulme (1859-1954). I shall argue that, when compared to present-day models such as FRBR and BIBFRAME 2.0, Hulme's classification of book attributes can be legitimately viewed as an early $20^{\text {th }}$-century bibliographical model avant la lettre.

\section{E. Wyndham Hulme}

The son of a prominent London surgeon and an alumnus of Oxford University, Edward Wyndham Hulme spent his entire career at the Patent Office of Great Britain, initially as a higher division clerk, then as assistant librarian, and, finally, from 1894 until his retirement in 1919, as librarian (Obituaries 1953, 273-274; Munford, 1987, 38; Obituary 1954). Among latter-day theorists of knowledge organization, he is remembered chiefly as the originator of the principle of literary warrant (e.g., Barité 2009, 14-16; Beghtol 1986, 111-112; Budd \& Martínez-Ávila 2016, 142-143; Olding 1968; Rodriguez 1984; Svenonius 2000, 135; Howarth \& Jansen 2014, 217), according to which "[a] class heading is warranted only when a literature in book form has been shown shown to exist" (Hulme 1950 [1911-1912], 9), and, to a somewhat lesser extent, as an early proponent of "statistical bibliography" (Hulme 1923), a quantitative approach to analyzing the development of scientific and technological literature (pp. 32-33) that prefigured bibliometrics (e.g., Hertzel 2003, 292; López 1996, 15; Pritchard 1969). Yet the interest of Hulme's thought for the history and theory of knowledge organization is not limited to these seminal ideas. Although his writings on cataloging and classification are few in number and fairly compact in formulation (Hulme 1900, 1901, 1902, 1903, 1906, 1950 [1911-1912], 1948), they contain a number of stimulating ideas and insights that have not hitherto received much attention from students of knowledge organization, such as the one considered here.

\section{Hulme's Classification of Book Attributes: A Bibliographic Model of the Book}

Hulme's classification of book attributes occurs in an essay on the "Principles of Book Classification" that was first published seriatim in the pages of the Library Association Record in 1911-1912 (Hulme 1950 [1911-1912]). As the title of this treatise indicates, Hulme sought to outline in it the first principles for the design of book classifications. The classification of books, he argued, is "mechanical" in nature, in that it involves "the mechanical ordering of material objects" (p. 1). In Hulme's view, the goal of ordering books is to achieve efficiency in literature-based research: as he put it, "book classification is a mechanical time-saving operation for the discovery of knowledge in literature" (p. 2; cf. p. 4; Hulme 1903, 29-30). Hulme understood the creation of a book classification to 
Thomas Dousa. 2017. E. Wyndham Hulme's Classification of the Attributes of Books: On an Early Model of a Core Bibliographical Entity.

NASKO, Vol. 6. pp. 21-38.

involve four processes: (1) the "definition" of class headings; (2) "registration", or assignment, of books to classes "in accordance with their definition"; (3), the "coordination", or arrangement, of class headings "in an order indicative of some common relationship"; and (4) "notation", or the creation of a "shorthand symbolization of the classes" that enables one to locate "the relative position" of any given class within a sequence of classes "without the recital of the class headings" (Hulme 1950 [1911-1912], 4). By means of these processes, he averred, books can be "classified in two ways": "directly on the shelves" or "indirectly by their titles in the class catalogue" (p. 3). Hulme held that shelf and catalogue classification are the same "in kind" though differing "in extent" (p. 3): the fact that books constitute physical units imposes constraints on shelf classifications that are not operative in the catalogue (Hulme 1901, 511; 1902, 326; 1948). Nevertheless, he favored the use of the book, or "work", ${ }^{1}$ as the unit of registration for shelf and catalogue classification alike, looking somewhat askance at analytical entry in the case of the latter (Hulme 1902, 319-320; 1903, 30-31; 1950 [1911-1912], 10-11, 15).

For Hulme, then, the book is the bibliographical entity of preeminent interest for bibliographical classification. In his view, if a classification of books is to fulfill its purpose and contribute to the efficiency of literature-based research, it is necessary that "the attributes by which a collection is classified correspond with those of which the reader is in search" (Hulme 1950 [1911-1912], 4). This consideration led him to devote the second

\footnotetext{
${ }^{1}$ Hulme's understanding of the relationship of the terms "book" and "work" is not easy to discern since he did not give an explicit definition of either in his writings. Some passages suggest that, for him, the terms were largely interchangeable (cf. Hulme 1902, 323). For example, Hulme (1950 [1911-1912]) characterized books as "material objects" (p. 1), as "concrete aggregates of facts selected from the common stock of knowledge" (p. 9), and as sites of the "physical aggregation of [sci., subject-TMD] matter" (p. 10), while describing works as "units-concrete and generally indivisible things ... [that] are called for, delivered to the public and replaced on the shelf" (Hulme 1914, 2): on this view, both books and works are concrete, material objects forming distinct physical units. On the other hand, other passages hint at a distinction between book and work. For instance, in reviewing possible units of registration within a classed catalogue, Hulme $(1903,31)$ observed that "your unit must be based upon bibliographical considerations, viz.: the series, the work, the volume, the chapter or the paragraph" (cf. Hulme 1902, 319). Here the "work" is distinguished from the "volume" and so works cannot be equated tout court with single physical volumes. It is just possible that Hulme made this distinction to accommodate multivolume works, though this cannot be proven for lack of documentation. It thus appears that Hulme was not entirely consistent in his understanding of the concepts of "book" and "work", sometimes using them as equivalent terms and sometimes treating them as if they had slightly different senses. In this, he was, in large measure, a child of his time: other contemporary theorists of cataloging and classification, such as Cutter, also used "book" and "work" interchangeably, while appearing to make implicit distinctions between books and works in some passages of their writing (Smiraglia 2001, 19). As we shall see, the lack of a sharp distinction between the concept of book and that of work is one feature of Hulme's thought that differentiates his early $20^{\text {th }}$-century bibliographical model from later ones.
} 
Thomas Dousa. 2017. E. Wyndham Hulme's Classification of the Attributes of Books: On an Early Model of a Core Bibliographical Entity.

NASKO, Vol. 6. pp. 21-38.

chapter (i.e., section) of his essay to an exploration of the attributes that books possess and by which they may be classified. ${ }^{2}$

Hulme (1950 [1911-1912], 4) began by observing that, in theory, "the choice of attributes by which books may be classified is unlimited". However, he immediately went on to add that, in practice, there is a significant difference on this score between the two fields most closely associated with the classification of books: bibliography and library classification. Bibliographers choose from among a wide range of attributes with which they determine the scope, and organization of, their bibliographies, while the designers of library classifications, as a rule, confine themselves to only "a few essential attributes of books" (p. 4). To afford the widest possible scope for discussion, Hulme proposed examining attributes of books used as "principles of division" (p. 5) in bibliography as well as those utilized for this purpose in library classification. In this, he drew inspiration from the Scottish chemist and bibliographer John Ferguson (1838-1916) (Weston 2000), who, in a treatise entitled Some Aspects of Bibliography, had identified no fewer than sixteen (kinds of) attributes employed by bibliographers to determine the scope of their bibliographies (Ferguson 1900, 12-22). ${ }^{3}$ Taking Ferguson's list as a point of departure, Hulme drew up "a systematic classification of the principles of division employed in book classification" (1950 [1911-1912], 5), ${ }^{4}$ which is the central object of our interest here and is represented in diagrammatic form in Figure 1 below. In elaborating this classification, Hulme had in mind both the attributes of books in the strict sense of the term and the categories of bibliographies constructed on the basis of such attributes: accordingly, he adduced both characteristics of books and kinds of bibliographies as examples in his discussion of the classes within the classification.

Hulme (1950 [1911-1912] 5) initially distinguished between "two primary classes" of bibliographical attributes: "[a]ccidental attributes, acquired by books subsequent to their

\footnotetext{
${ }^{2}$ It was not uncommon for early $20^{\text {th }}$-century writers on cataloging and library classification to discuss the various attributes of books that could potentially be classified in a catalog or on the shelves as part of the exposition of the method of classification; two prominent contemporaries who did so were Charles Ammi Cutter in his Rules for a Dictionary Catalog (Cutter 1904, 15) and Ernest Cushing Richardson in his Classification, Theoretical and Practical (Richardson 1901, 60-65). Hulme thus followed a standard topos in discussing this issue, although, as we shall see, he developed the idea in a unique way.

3 These principles of determining scope are: (1) date; (2) place (sci., of printing), (3) printer, (4) material, (5) type (i.e., typeface), (6) size, (7) illustrations, (8) language, (9) subject, (10) groups of writers, (11) individual authors, (12) single books, (13) anonymous and pseudonymous books, (14) 'Curiosa', facetiae' and suppressed books, (15) rarities (i.e., rare books), and (16) generality (i.e., the lack of any limitation in scope, characteristic of general, or universal bibliographies, which Ferguson glossed as "general works").

4 Interestingly, Ferguson $(1900,12)$ had already imposed his own rudimentary classification on the "bibliographical characteristics" determining the scope of bibliographies, according to which "the scope of a bibliography may be either technical, dictated by pecularities of the books; or literary, by similitude of topic" [emphases mine-TMD]. The former of these two categories appears to correspond primarily to Hulme's accidental attributes and inseparable physical attributes, while the latter seems to bear analogy to Hulme's inseparable non-physical attributes.
} 
Thomas Dousa. 2017. E. Wyndham Hulme's Classification of the Attributes of Books: On an Early Model of a Core Bibliographical Entity.

NASKO, Vol. 6. pp. 21-38.

issue", and "[i]nseparable attributes," that is to say, "attributes inherent in books prior to such issue." Underlying this distinction is the assumption that publication is a decisive point in the life cycle of books, one that is rife with ontological implications. The attributes that a given book possesses at the time of publication are "inherent" to it, whereas those that it comes to possess after publication are "accidental", or contingent "upon circum-

Figure 1: Hulme's Classification of Book Attributes

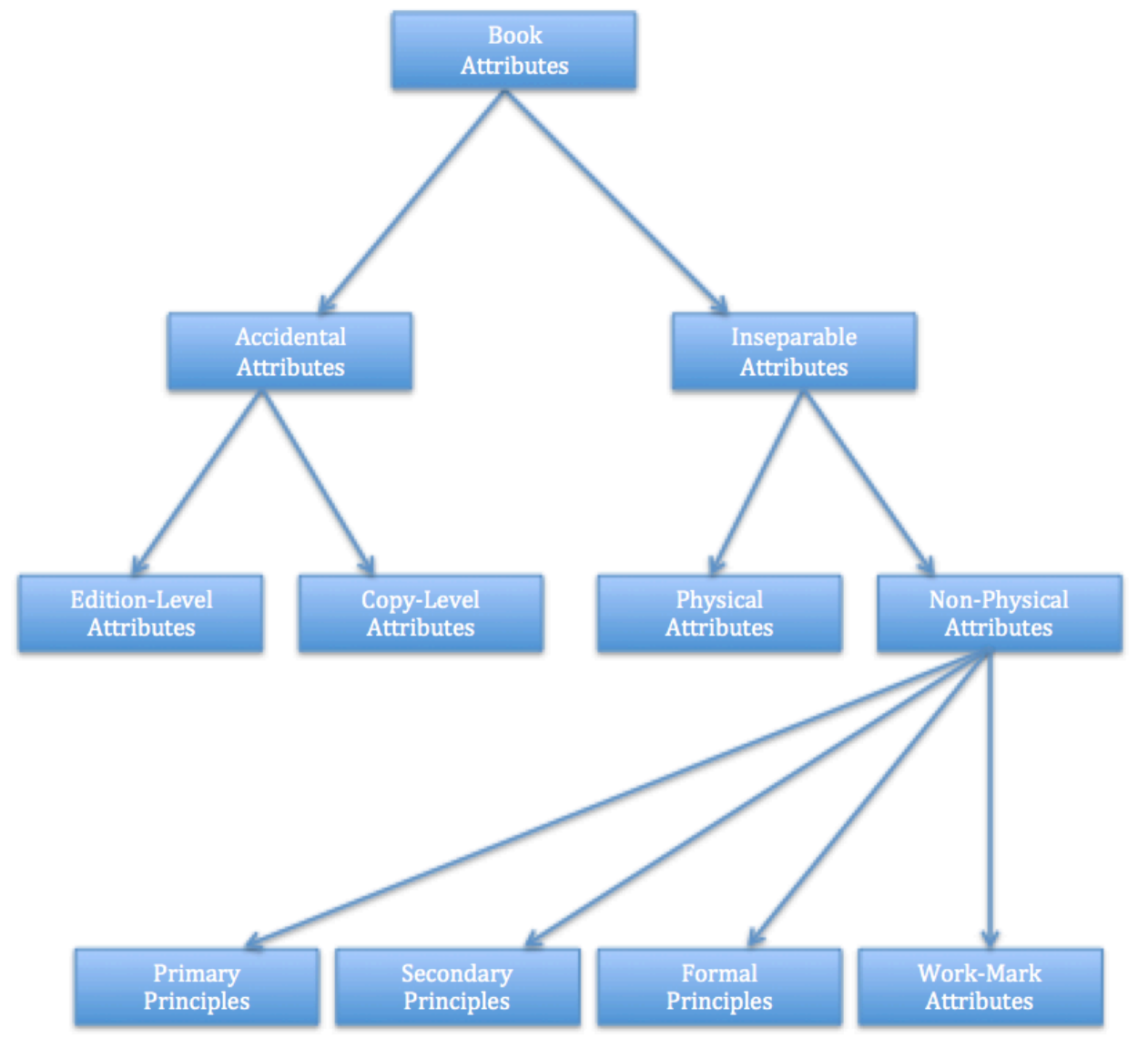

Source: after Hulme 1950 (1911-1912), 5-6.

stances of [its] life history": the former are thus constitutive to the identity of books in a way that the latter are not. ${ }^{5}$

\footnotetext{
${ }^{5}$ Hulme's use of the term "accidental" is significant here, for, in traditional logic, the term "accident" may denote "an attribute that is not characteristic of or essential to a nature [sci., a kind of thing--
} 
Thomas Dousa. 2017. E. Wyndham Hulme's Classification of the Attributes of Books: On an Early Model of a Core Bibliographical Entity.

NASKO, Vol. 6. pp. 21-38.

Having established this initial division, Hulme (1950 [1911-1912], 5) proceeded to subdivide the class of accidental attributes into two subordinate classes: those attributes that are "common to an edition or portion of an edition" and those that are "peculiar to single copies of works". We shall call these "edition-level" and "copy-level" accidental attributes respectively. For Hulme, edition-level accidental attributes encompassed those attributes of an edition that arose out of general social or natural circumstances relating to its circulation following publication. He cited proscription, or censoring, by a state or other authority; destruction by disasters like fires; and rarity of availability - hence price, or market valueas examples of accidental attributes attaching to an edition as a whole, and adduced registers of book-prices, book-sellers' catalogues, and auctioneers' booklists as kinds of bibliographies in which such attributes are of central importance. ${ }^{6}$ In Hulme's view, the class of edition-level accidental attributes is relatively small. Much more numerous, he averred, are copy-level accidental attributes. These encompass not only the property of belonging to a particular owner but all "attributes founded on modifications effected in books by their owners", such as annotations and various forms of physical alterations, such as "inlaying to larger size" or rebinding (p. 5). Interestingly, Hulme argued that the scope of "all administrative catalogues and registers of libraries, public and private" is circumscribed by a copy-level accidental attribute, on the grounds that "all proprietary catalogues primarily assert, and are consequently subject, to the ownership limitation": after all, the catalog of any given library seeks to account only for those books that fall within that library's holdings (p. 5). For Hulme, then, copy-level accidental attributes are ultimately rooted in the ownership history of individual copies of books and the events befalling them within the framework of this history, in contradistinction to edition-level accidental attributes, which are affected by larger-scale forces originating outside of the framework of the relationship between the owner and the owned.

After considering accidental attributes, Hulme (1950 [1911-1912], 6) turned his attention to the second primary class in his classification, that of inseparable attributes, or

TMD] but may be present or absent in different members of the same species [sci., class--TMD]" (Wuellner 2012 [1956], 2). With the aid of this logical notion, Hulme's point may be restated thus: if one considers a given edition of a given work to constitute a class, the members of which are the individual copies of the edition, then inseparable attributes are attributes possessed by all members of the class at the time of publication, while accidental attributes are those that may or may not be possessed by members of the class as a result of their individual histories subsequent to publication. From this, it follows that the inseparable attributes possessed by all members of the class at the time of publication are more constitutive of the definition of the class than the accidental attributes possessed by individual members as a result of their subsequent histories. One should note, however, that Hulme also accepted the existence of accidental attributes possessed by all copies of a given edition as a result of historical circumstances affecting the edition as a whole subsequent to publication: the distinction between these attributes and inseparable attributes lies in the fact that the latter were present in the edition at the time of publication, while the former accrued to it after publication. This underscores the importance that publication had as an element in Hulme's definition of inseparable and accidental attributes of books.

${ }^{6}$ The attributes of proscription and market value correspond to Ferguson's categories of (14)

“"Curiosa", "facetiae", and suppressed books" and (15) "rarities", respectively (see n. 3 above). 
"attributes inherent in books at their date of issue". These he subdivided into two subordinate classes: "[p]hysical attributes" and "[n]on-physical attributes" (p. 6). The category of inseparable physical attributes covers such properties as place of printing, printer, the material from which the book is made, the kind of typeface used in its creation, its size, and the presence of illustrations - in short, those aspects of books that govern "the mechanical constitution and make-up of books" (p. 6). ${ }^{7}$ According to Hulme, the physical inseparable attributes of books form the basis for "the science of mechanico-historical bibliography"-what today would be called "analytical" or "critical" bibliography (Stokes 2003, 283-284) - "a science which classifies literature by the mechanical characteristics of its typography and execution in so far as these throw light upon its common origin or provenance" (Hulme 1950 [1911-1912], 6). By contrast, he claimed, the inseparable physical attributes of books play a relatively restricted role within library classification, citing the treatment of manuscripts as distinct collections within a library and the partitioning of books in a collection by size as examples of ways in which such attributes affect the organization of materials in this domain.

Figure 2: Hulme's Classification of Principles of Division Based on Non-Physical Inseparable Attributes of Books and Catalogs

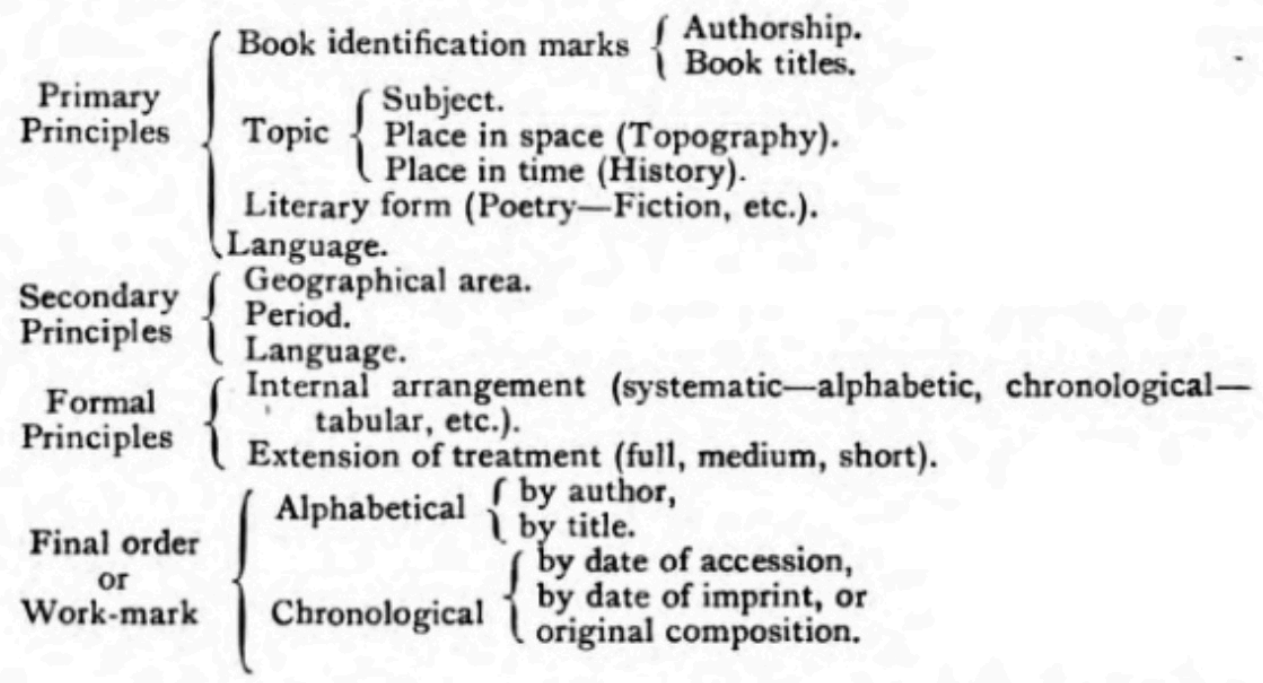

Source: Hulme 1911-1912, 392.

\footnotetext{
7 These attributes correspond to the following categories in Ferguson's list of bibliographical characteristics: (2) place (sci., of printing), (3) printer, (4) material, (5) type (i.e., typeface), (6) size, and (7) illustrations (see n. 3 above).
} 
The final class identified by Hulme (1950 [1911-1912] 6) is that of "inseparable and non-physical classes of books", interest in which, he asserted, is "common both to the bibliographer and library classifier." Claiming lack of space, he did not discuss this class in any detail but offered instead an extensive diagram of its subdivisions, which is reproduced as Figure 2 above. As this diagram shows, Hulme divided inseparable non-physical attributes into four separate subclasses-namely, "primary principles", "secondary principles", "formal principles" and principles relating to the "final order or work-mark" in a bibliography or library catalog (or shelf). Inasmuch as he did not provide further commentary on the formation of this set of subdivisions, its rationale must be, in large measure, reconstructed.

The primary principles by which books may be classified encompass four subclasses: attributes that help to identify books (namely, their author and their title); the topics to which their contents pertain (further subdivided into subjects, places in space, and place in time); literary form; and language. ${ }^{8}$ These attributes appear to have been designated as primary because of their importance in the constitution of library catalogs - this is especially true of titles and authors - and classifications. At first blush, the modern reader may find it puzzling that Hulme should have regarded the author as a non-physical attribute of a book, for authors are, as a rule, eminently flesh-and-blood creatures. Hulme's decision becomes intelligible if one realizes that he was treating authors as attributes of books rather than as entities in their own right. Because authors are the ultimate causes of books, they cannot be regarded as accidental attributes; furthermore, insofar as authors are not physically parts of books, they cannot be included among the inseparable physical attributes thereof. Within the framework of Hulme's classification, then, the class of inseparable nonphysical attributes was the most appropriate location for authors qua attributes. Hulme appears to have been aware of the conceptual awkwardness of treating authors as nonphysical attributes, for in his classificatory table, he used the abstract noun "authorship" instead of the concrete term "author".

When we turn to the three secondary attributes enumerated by Hulme, we find that they recapitulate two of the classes falling under the topic subclass (i.e., "geographical area" and "period") and the language subclass. His statement that "certain principles of division appear at several stages of the act of classification" (Hulme 1950 [1911-1912], 7) strongly suggests that these secondary principles represent criteria used to subdivide certain of the primary principles: for example, subject might be further subdivided by geographical area and/or period and literary form, by language, period or geographical area.

The formal principles of "internal arrangement" and "extension of treatment", on the other hand, appear not to relate to books being classified but rather to reflect the formal

\footnotetext{
${ }^{8}$ These categories find the following analogues in Ferguson's list of bibliographic categories: (8) language, (9) subject, (10) groups of writers, (11) individual authors, (12) single books, (13) anonymous and pseudonymous books (see note 3, above). Ferguson's "single books" and "anonymous and pseudonymous books" correspond approximately to Hulme's attribute of "book titles" and those of "individual authors" and "groups of writers" to that of "authorship"; "subject" evidently relates to Hulme's "topic" and "language" is the same for both Ferguson and Hulme.
} 
Thomas Dousa. 2017. E. Wyndham Hulme's Classification of the Attributes of Books: On an Early Model of a Core Bibliographical Entity.

NASKO, Vol. 6. pp. 21-38.

attributes of the bibliographies and library catalogs: ${ }^{9}$ as such, they represent what could be called the "outer form" (Sayers 1926, 81) of the latter. By the same token, the category of principles governing the "final order or work-mark" has, on the face of it, less to do with the attributes of books per se than with the manner in which they may be ordered-in Hulme's parlance, "co-ordinated"-within a bibliography or catalog or on the shelf. This latter category is the theoretically most problematic in Hulme's classification, for several of the principles of ordering that it includes do not seem to fit easily within the category of non-physical inseparable attributes to which he assigned them. The principle of ordering by author and title can be viewed as an extension of these two attributes. However, chronological ordering by date of accession is based on the fact of ownership, which Hulme had defined as a copy-level accidental attribute, and ordering by date of imprint invokes a characteristic that he had ranged among physical inseparable attributes. One possible explanation for these theoretical inconcinnities is that Hulme considered the category of final order to be a further development of the category of formal principles and so viewed it as being analogous to literary form, one of the primary non-physical inseparable attributes. However this may have been, it seems that he was unable to avoid a certain degree of internal theoretical conflict in his classification of the principles of division used to structure bibliographies, catalogs, and shelf classifications.

At the end of his discussion of the various attributes by which books might be classified, Hulme (1950 [1911-1912], 7) came to the conclusion that

[f]or the primary requirements of library service it will be seen two distinct classifications are needed:

A. An arrangement of works by marks which will best conduce to their ready identification, i.e., by their authors or titles.

B. A classification based upon the most important intrinsic characteristics of books, viz. their topic or literary form.

The former of these classifications is especially useful for the alphabetically organized author-title catalog, which Hulme characterized as an "index classification", the purpose of which is to serve as an efficient "finding list" (p. 7; cf. Hulme 1906, 40-41). The latter, on the other hand, functions as a "good subject guide" and is more appropriate for the class catalog and shelf classification (Hulme 1901, 508; 1950 [1911-1912], 7-8). Now Hulme's views about the preeminent role accorded to non-physical inseparable attributes, such as author, title, subject, and literary form, within library catalogs and shelf classifications were hardly novel. Indeed they reflected a consensus among librarians of his generation, neatly summarized by Cutter $(1904,15)$, that "books are most commonly brought together in catalogs because they have the same authors, or the same subjects, or the same literary form, or are written in the same language ...". Yet, if Hulme's conclusions were conventional, they were the result of a truly original attempt to chart the space of possible

9 Significantly, Hulme's characterization of internal arrangement as either "systematic" or "alphabetic" and extension of treatment as "full", "medium", and "short" echoes the language of Cutter's discussion of catalogues in Rules for a Dictionary Catalog (cf. Cutter 1904, 11 ["Short", "Medium", and "Full"], 17-18 ["alphabetical" vs. "systematic"]): it thus appears virtually certain that he had primarily catalogues in mind here. 
Thomas Dousa. 2017. E. Wyndham Hulme's Classification of the Attributes of Books: On an Early Model of a Core Bibliographical Entity.

NASKO, Vol. 6. pp. 21-38.

ways in which books might be classified: the creation of a taxonomy of the attributes of books. To be sure, this taxonomy has the character of a preliminary sketch rather than that of a fully worked-out product and, as we have seen, it is not free of theoretical difficulties. Nevertheless, insofar as Hulme sought to give a systematic account of the different kinds of attributes of books by means of which books might be set into relation to one another within the framework of a bibliography, a library catalog, or a library shelf, his classification may be viewed as a pioneering model of the book as a bibliographical entity, albeit one that did not present itself as a model in the current sense of the term.

\section{Mapping Hulme's bibliographic model to FRBR and BIBFRAME 2.0}

Thus far, analysis of Hulme's classification of the attributes of books has led us to the conclusion that his taxonomy can be considered to be an implicit bibliographical model of the book. A complementary way of establishing the model-like nature of Hulme's taxonomy is to map his categories of book attributes to current bibliographical models such as FRBR and BIBFRAME. At the outset, it is important to acknowledge that Hulme's classification differs in three fundamental ways from these present-day bibliographical models. First, Hulme (1950 [1911-1912], 2) wrote as if libraries confined their collections almost exclusively to books: as he put it, "books are our theme." ${ }^{10}$ FRBR and BIBFRAME, on the other hand, are predicated on the assumption that libraries collect a wide variety of information resources (e.g., sound recordings, video recordings, electronic resources), not just books, and that all such resources can be accommodated within the model (e.g., Souček, Souček, \& Drobíková 2013, 130, s.v. “Zhmotnění”). Second, Hulme’s taxonomy acknowledged a single bibliographical entity - the book: by contrast, FRBR and BIBFRAME each includes multiple bibliographical entities within its framework. Finally, Hulme's classification presupposed a simple dyadic relationship between a given kind of entity - the book - and its attributes. FRBR and BIBFRAME, however, posit-each in its own way-a primarily triadic relational structure in which entities are linked to one another by means of relationships. At first sight, then, it may appear that to attempt to map Hulme's taxonomy to these two bibliographical models is to seek to compare apples and oranges. Nevertheless, it is worth undertaking such an exercise: after all, apples and oranges are both kinds of fruit and one may well uncover interesting unities underneath the differences.

Before proceeding to the mapping itself, it will be helpful to recall some relevant features of FRBR and BIBFRAME. FRBR posits the existence of four different bibliographical entities: the "Work", the "Expression", the "Manifestation", and the "Item" (IFLA Study Group on the Functional Requirements for Bibliographic Records, 1998, 12). A Work is defined as "a distinct intellectual or artistic creation"; an Expression is "an

\footnotetext{
${ }^{10}$ Some modern commentators have suggested that, within the framework of Hulme's theory, "book" is to be understood as "any piece of written information to be classified" (Rodríguez 1984, 18) or "for literature in all its forms, and for ... representations of literature (catalog and index entries)" (Olding 1968 , 6). Such interpretations do not seem, however, to be borne out by Hulme's descriptions of books, which emphasize their character as discrete "physical bibliographical units" (Olding 1966, 105): rather, they reflect an understandable desire on the part of the commentators to extend Hulme's ideas to smaller-scale works, such as articles, that form only parts of physical volumes.
} 
Thomas Dousa. 2017. E. Wyndham Hulme's Classification of the Attributes of Books: On an Early Model of a Core Bibliographical Entity.

NASKO, Vol. 6. pp. 21-38.

intellectual or artistic realization of a work within a semiotic system (významotvorným systému)"; a Manifestation is "the physical embodiment of the expression of a work"; and an Item is "a single exemplar of a manifestation" (Souček, Souček, \& Drobíková 2013, 130, s.v. "Zhmotnění"). As is manifest from these definitions, the four entities stand in a series of interlocking relations: a Work "is realized in" an Expression; an Expression "is embodied in" a Manifestation; and a Manifestation "is exemplified by" an Item (IFLA Study Group on the Functional Requirements for Bibliographic Records, 1998, 13). Taken together, these four entities represent an "abstraction hierarchy" (Albertsen \& Van Nuys 2005,130 ), with the Work being the most abstract and the Item being the most concrete. All four of these entities, known collectively as Group 1 entities, refer to different aspects of a given resource: Work and Expression cover its abstract conceptual and semiotic aspects; Manifestation has to do with its physical features in the abstract; and Item reflects its concreteness as an individual material thing (IFLA Study Group on the Functional Requirements for Bibliographic Records, 1998, 16, 18, 20, 23). Each of these four entities is defined as possessing a set of attributes: moreover, the Group 1 entities can contract relationships with other kinds of entities including persons, families, and corporate bodies (known collectively as Group 2 entities) and subjects, objects, events, and places (known collectively as Group 3 entities (Coyle 2016, 91-92; IFLA Study Group on the Functional Requirements for Bibliographic Records, 1998, 14-15, 30).

Created in an environment in which FRBR principles had already exerted a palpable influence on cataloging standards and practice, BIBFRAME offers a comparable, but different, bibliographical model. To date, two versions of BIBFRAME have appeared. In the original version, the model defined four main entity types: Creative Work, Instance, Authority, and Annotation (Library of Congress 2012, 8; Mitchell 2013, 27). Creative Work was defined as "a resource essence of the cataloging item"; Instance, as "a resource reflecting an individual, material embodiment of the Work; Authority, as "a resource reflecting key authority concepts that have defined relationships reflected in the Work and Instance", such as "People, Places, Topics, Organizations, etc."; and Annotation as "a resource that decorates $[\mathrm{sic}]$ other BIBFRAME resources with additional information" (Library of Congress 2012, 8). Of the two primary bibliographical entities in this model, Creative Work and Instance, the former was broadly analogous to Work and Expression in FRBR, while the latter corresponded roughly to Manifestation: Authority, in turn, was an analogue to Group 2 and 3 entities in FRBR, while Annotation could be partially mapped onto Item (Coyle 2016, 145; Shaw 2017, 185). The most recent version, known as BIBFRAME 2.0, has introduced some changes in the model that align it more closely to FRBR. Most notably, the number of core bibliographical entities has been expanded from two to three-Work, Instance, and Item-with, Work, again, corresponding broadly to FRBR's Work and Expression; Instance, to FRBR's Manifestation; and Item, to FRBR's Item (Library of Congress 2016; MacCallum 2016, 116-117), while the Authority class has been decomposed into Agents, Subjects, and Events classes and the Annotation class has been eliminated (Library of Congress, 2016, n.d.). Here, we shall take BIBFRAME 2.0 as our point of reference.

Having briefly reviewed the main features of the FRBR and BIBFRAME 2.0, we are now in a position to explore how Hulme's classification of book attributes can be mapped 
Thomas Dousa. 2017. E. Wyndham Hulme's Classification of the Attributes of Books: On an Early Model of a Core Bibliographical Entity.

NASKO, Vol. 6. pp. 21-38.

onto them. Let us begin with his inseparable non-physical attributes. As we saw earlier, the most important subclass of this category is Hulme's set of "primary principles": the other subclasses either recapitulate attributes found in the primary principles (e.g., "secondary principles") or refer to features of catalogs, bibliographies, or classifications (e.g., "formal principles" and "final order or work-mark") and so can, for our purposes, be left out of account. The four primary principles encompassed title, author, topic, literary form, and language. Within FRBR, these are all associated with either the Work or the Expression entity. FRBR includes "Title of the Work" and "Form of the Work" among the attributes of the Work, while stipulating that Works are "created by" persons or corporate bodies, who are thus accorded a role analogous to that of Hulme's author, and that Works have subjects (IFLA Study Group on the Functional Requirements for Bibliographic Records, 1998, 13$16,33) ;{ }^{11}$ language, on the other hand, is an attribute of Expression (p. 36). BIBFRAME 2.0, on the other hand, stipulates that authors, languages, and subjects are all related to the Work (Library of Congress 2016). ${ }^{12}$ In general terms, then, Hulme's inseparable non-physical attributes are most readily comparable to attributes and relationships characteristic of FRBR's Work and Expression, and BIBFRAME 2.0's Work.

Hulme's other class of inseparable attributes, that of the inseparable physical attributes, included such features of a book as the place where it was printed, the printer, the material from which it was made, the kind of typeface used in its creation, its size, and the presence of illustrations. If one widens Hulme's bibliography-oriented focus on printing to include publication as well, then, within the framework of FRBR, his inseparable physical attributes find their closest analogues in those of the Manifestation, such as "Place of Publication/ Distribution" $(\approx$ place of printing), "Publisher/Distributor" $(\approx$ printer $)$, "Fabricator/ Manufacturer" ( $\approx$ printer), "Physical Medium" $(\approx$ material), "Typeface (Printed Book) $(\approx$ type), and "Dimensions of the Carrier" ( $\approx$ size) (IFLA Study Group on the Functional Requirements for Bibliographic Records, 1998, 42-45). BIBFRAME 2.0 associates attributes of this kind primarily with the Instance, which has to do with "publisher, place and date of publication, and format", as well as "dimensions", "base material", and other physical aspects of a resource (Library of Congress 2016; Library of Congress n.d. b, s.v. "Dimensions", "baseMaterial"). BIBFRAME 2.0 includes a property absent from FRBR, "illustrative content" ( $\approx$ illustrations $)$, which it ascribes to Works and Instances alike

\footnotetext{
${ }^{11}$ It should be noted that FRBR also assigns the title as an attribute to Expressions and Manifestations (IFLA Study Group on the Functional Requirements for Bibliographic Records, 1998, 36, 41): this reflects the fact that, in cataloging, the uniform title of an item being cataloged (i.e., title of the Work) may not coincide, in terms of linguistic form (i.e., title of the Expression) with the form of a title found in a particular edition of a work (i.e., title of the Manifestation). In other words, the title of the Manifestation represents the title as it is printed in a given book; the title of the Expression represents the abstract character string represented by the title as it is printed in the book; and the title of the Work represents the title in the abstract. Since Hulme did not distinguish between these different aspects of the title, his attribute of title can be, in principle, identified with all three of these FRBR attributes.

12 According to the most recent version of the BIBFRAME ontology, the attribute of "Title" can be associated with "Work", "Instance", or "Item" (n.d. b, s.v. "Title" [2016-04-21 (New)]): The multilevel applicability of the Title to bibliographical entities within the model mirrors that of FRBR.
} 
Thomas Dousa. 2017. E. Wyndham Hulme's Classification of the Attributes of Books: On an Early Model of a Core Bibliographical Entity.

NASKO, Vol. 6. pp. 21-38.

(Library of Congress n.d. b, s.v. "illustrativeContent"). With some slight deviations, then, Hulme's physical inseparable attributes are analogous to the attributes of the Manifestation in FRBR and the Instance in BIBFRAME 2.0.

It remains to consider the other two classes of attributes in Hulme's classificationedition-level and copy-level accidental attributes. Edition-level accidental attributes comprised properties of books that affected a given edition as a whole, such as proscription or censoring by a state or other authority, scarcity with regard to availability, and, accordingly, price. Mutatis mutandis, these attributes bear a rough analogy to the Manifestation-level attributes of "Terms of Availability" and "Access Restrictions on the Manifestation" in FRBR (IFLA Study Group on the Functional Requirements for Bibliographic Records, 1998, 45): by contrast, no corresponding attributes of this kind appear to be present in BIBFRAME 2.0. Copy-level accidental attributes, on the other hand, which included such features as ownership and alterations made to individual copies of books by their owners, can be mapped to both FRBR and BIBFRAME 2.0. In FRBR, they find their closest analogues in attributes of the item, such as "Provenance of the Item", which has to do with the ownership history of an item; "Marks/inscriptions", which relate to any inscriptions or annotations that have been added to an item and are unique to it; and "Condition of the Item", as well as in the "is owned by" relationship that relates items to persons or corporate bodies (pp. 14, 49-50). In BIBFRAME 2.0, correspondent properties include the "held by" property, which relates an Item to its owner, and "custodial history", which traces ownership history: interestingly, the latter can be applied to Works and Instances as well as Items (Library of Congress 2016; Library of Congress n.d. b, s.v. "heldBy", "custodialHistory"). With some slight divagations, then, Hulme's copy-level accidental attributes correspond to the attributes of the Item in FRBR and BIBFRAME 2.0 alike.

From the foregoing analysis, it is apparent that the various classes in Hulme's taxonomy of book attributes correspond, in large measure, to the clusters of properties (i.e., attributes and/or relationships) associated with the different bibliographical entities defined in the FRBR and BIBFRAME 2.0 bibliographical models. As we have demonstrated, the inseparable non-physical attributes of books in Hulme's classification are analogous to the properties of the Work and Expression in FRBR and the Work in BIBFRAME 2.0; inseparable physical attributes correspond to those of the Manifestation in FRBR and the Instance in BIBFRAME 2.0; edition-level accidental attributes likewise find analogues among the properties of FRBR's Manifestation; and copy-level accidental attributes are comparable to those of the Item in FRBR and BIBFRAME 2.0 alike (see Figure 3 below). The general correspondence of Hulme's categories of book attributes to the properties of different bibliographical entities in FRBR and BIBFRAME 2.0 is significant, for it suggests that, in his analysis of book attributes, Hulme was making conceptual distinctions similar to those of the designers of these latter-day bibliographical models. This bolsters the claim that his taxonomy of book attributes constitutes a bibliographical model of the book. Since Hulme did not conceptualize his taxonomy as a model in the strict sense of the term, it is best characterized as an implicit, or virtual, bibliographical model-that is to say, a bibliographical model avant la lettre. 
Despite the similarity in conceptual distinctions, there was one significant difference between Hulme's implicit bibliographical model and those of FRBR and BIBFRAME 2.0.

Figure 3: Hulme's Taxonomy of Book Attributes Mapped to The FRBR and BIBFRAME 2.0 Bibliographic Models

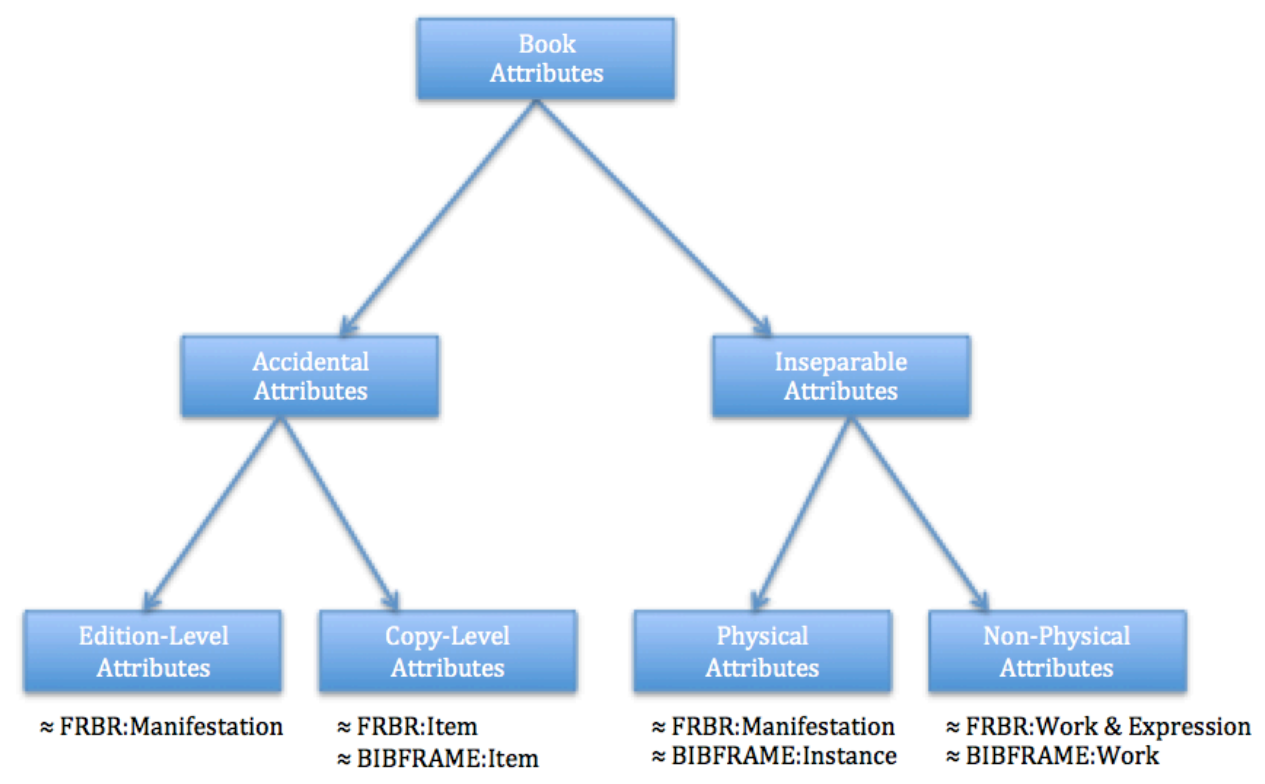

Unlike the designers of the latter models, who admitted several different bibliographical entities postulated as different levels in an abstraction hierarchy, Hulme posited only a single bibliographical entity. For this reason, he did not distribute the attributes that he identified across different bibliographical entities but rather clustered them into categories based on different metaphysical properties (separability vs. inseparability; physicality vs. non-physicality) of the single bibliographical entity that he recognized: the book.

\section{Conclusion}

In this paper, I have argued that the taxonomy of book attributes set forth by E. Wyndham Hulme in his "Principles of Book Classification" should be regarded as an implicit bibliographical model, one that antedates its modern counterparts by approximately eighty years. In support of this claim, I have demonstrated that the different categories of book attributes defined by Hulme can be mapped onto the clusters of categories associated with different bibliographical entities in FRBR and BIBFRAME 2.0. If one accepts as valid the characterization of Hulme's classification as an implicit bibliographical model, it remains to inquire what significance this has for the theory of knowledge organization. I 
Thomas Dousa. 2017. E. Wyndham Hulme's Classification of the Attributes of Books: On an Early Model of a Core Bibliographical Entity.

NASKO, Vol. 6. pp. 21-38.

suggest that the primary theoretical interest of Hulme's bibliographical model lies in the fact that it represents the structural relations between the different clusters of attributes belonging to a bibliographical resource in a way that differs markedly from that employed by current bibliographic models. To get a purchase on this requires that we take a broader historical perspective vis-à-vis the conceptualization of bibliographical entities.

Commentators on the history of cataloging generally agree that a major advance in the conceptualization of books and other units of literature took place in the twentieth century: the theoretical distinction between "works" (i.e., units of literature viewed as intellectual or artistic entities) and "items" (i.e., units of literature viewed as physical entities) (Petek 2004, 40-41). Although an implicit distinction between works and the various items in which they are manifested had been drawn by Thomas Hyde as early as the late $17^{\text {th }}$ century and buttressed by Antonio Panizzi in the second quarter of the $19^{\text {th }}$ century, it did not receive a fully articulated theoretical formulation until the middle decades of the $20^{\text {th }}$ century at the hands of Julia Pettee, Eva Verona, and Seymour Lubetzky (Smiraglia 2001, 16-22). This mid-century theoretical differentiation of works from items formed the basis for bibliographic models such as FRBR and BIBFRAME 2.0, which conceptually decompose books and other library resources into several interrelated bibliographic entities defined at different levels of abstraction.

Hulme, however, developed his bibliographical model at the beginning of the second decade of the $20^{\text {th }}$ century, a quarter of a century before the theoretical distinction between work and item was first explicitly formulated in library literature. He did not have the theoretical grammar for operating with such a distinction: indeed, in his writings, he used the words "books" and "works" more-or-less interchangeably (see n. 1 above). Hulme's taxonomy of book attributes is thus a rare example of a bibliographical model constructed before the theoretical split between works and items and, hence, before the proliferation of bibliographical entities within bibliographical models. One result of this is that, as has been stressed through this paper, his bibliographical model acknowledges a single bibliographical entity: the book. Yet, Hulme distinguished between different metaphysical aspects of this entity - physicality vs. immateriality, inherent properties vs. secondarily acquired properties - that required partitioning the attributes that he had identified into separate clusters. Had he been working within the framework of a bibliographic model possessing multiple bibliographic entities ranged in an abstraction hierarchy, he could have assigned these clusters of attributes to different entities at the appropriate level of abstraction, as the designers of FRBR and BIBFRAME 2.0 have done. However, because that theoretical option was foreclosed to him through the limitations of his own model, he expressed these metaphysical differences in the form of a classification: the different kinds of attributes became different classes of attributes related to a single bibliographical entity rather than being distributed across different bibliographical entities. Hulme's taxonomy of bibliographical attributes thus shows how a bibliographical model possessing a single bibliographical entity can be structured to represent different levels of abstraction with respect to the attributes of that entity. Needless to say, the path that he blazed out with his taxonomy is a road that was not taken by later designers of bibliographical models. Perhaps it would have led to a dead end. Nevertheless, it offers an interesting historical alternative 
Thomas Dousa. 2017. E. Wyndham Hulme's Classification of the Attributes of Books: On an Early Model of a Core Bibliographical Entity.

NASKO, Vol. 6. pp. 21-38.

to current assumptions about how to conceptualize and structure the relationship between attributes and entities in the bibliographical universe.

\section{References}

Albertsen, K. \& van Nuys, C. (2005). Paradigma: FRBR and digital documents. Cataloging \& Classification Quarterly, 39(3/4), 125-149.

Barité, Mario. 2009. Garantía literaria y normas para construcción de vocabularios controlados: aspetos epistemológicos y metodológicos. Scire, 15(2): 13-24.

Beghtol, Clare. 1986. Semantic Validity: Concepts of Warrant in Bibliographic Classification Systems. Library Resources \& Technical Services, 30: 109-125.

Budd, John M., \& Martínez-Ávila, Daniel. 2016. Epistemic Warrant for Categorizational Activities in Knowledge Organization. In Knowledge Organization for a Sustainable World: Proceedings of the Fourteenth International ISKO Conference, 27-29 September 2016, Rio de Janeiro, Brazil, ed. José Augusto Chaves Guimarães, Suellen Oliveiri Milani, Vera Dodebei. Advances in Knowledge Organization, Vol. 15. Würzburg: Ergon Verlag, 142-145.

Chen, Peter Pin-Shan. 1976. The Entity-Relationship Model-Toward a Unified View of Data. $A C M$ Transactions on Database Systems, 1(1): 9-36.

Coyle, Karen. 2016. FRBR, Before and After: A Look at Our Bibliographical Models. Chicago: ALA Editions.

Croissant, Charles R. 2012. FRBR and RDA: What They Are and How They May Affect the Future of Libraries. Theological Librarianship, 5(2): 6-22. Available at: https://theolib.atla.com/theolib/article/view/234

Cutter, Charles A. 1904. Rules for a Dictionary Catalog. Fourth Edition, Rewritten. U.S. Bureau of Education: Special Report on Public Libraries-Part II. Washington: Government Printing Office.

Ferguson, John. 1900. Some Aspects of Bibliography. Edinburgh: George P. Johnston.

Hertzel, Dorothy H. 2003. Bibliometrics History. In Encyclopedia of Library and Information Science, Second Edition. Volume 1, ed. Miriam A. Drake. New York/Basel: Marcel Dekker, Inc., 288-328.

Howarth, Lynne C., \& Jansen, Eva Hourihan. 2014. Towards a Typology of Warrant for $21^{\text {st }}$ Century Knowledge Organization Systems. In Wiesław Babik (ed.), Knowledge Organization in the $21^{\text {st }}$ Century: Between Historial Patterns and Future Prospects: Proceedings of the Thirteenth International ISKO Conference, 19-22 May 2014, Kraków, Poland, ed. Wiesław Babik. Advances in Knowledge Organization, Vol. 14. Würzburg: Ergon Verlag, 216-221.

Hulme, E. Wyndham. 1900. Principles of Dictionary Subject-Cataloguing in Scientific and Technical Libraries. The Library Association Record, 2: 43-571-576.

Hulme, E. Wyndham. 1901. On the Construction of the Subject Catalogue in Scientific and Technical Libraries. Library Association Record, 3: 507-513.

Hulme, E. Wyndham. 1902. On a Co-operative Basis for the Classification of Literature in the Subject Catalogue. The Library Assocation Record, 4: 317-326.

Hulme, E. Wyndham. 1903. Classification in the Patent Office Library. The Library Assistant, no. 72: 27-33.

Hulme, E. Wyndham. 1906. The Principles of Cataloguing. The Library Association Record, 8: 3145.

Hulme, E. Wyndham. 1914. Ideals: Old and New: An Address to Young Librarians. The Library Assistants' Association Series, 5. Croydon: [The Library Assistants' Association] 
Thomas Dousa. 2017. E. Wyndham Hulme's Classification of the Attributes of Books: On an Early Model of a Core Bibliographical Entity.

NASKO, Vol. 6. pp. 21-38.

Hulme, E. Wyndham. 1923. Statistical Bibliography in Relation to the Growth of Modern Civilization: Two Lectures Delivered in the University of Cambridge in May, 1922. London: Grafton \& Co.

Hulme, E. Wyndham. 1948. The Future of Classification. The Library Association Record, 50: 79.

Hulme, E. Wyndham. 1950 [1911-1912]. Principles of Book Classification. A.A.L. Reprints No. 1. London: The Association of Assistant Librarians. [Originally published in: The Library Association Record, 13, 1911: 354-358, 389-394, 449; 14, 1912: 39-44, 174-181, 216-221]

IFLA Study Group on the Functional Requirements for Bibliographic Records. 1998. Functional Requirements for Bibliographic Records: Final Report. UBCIM Publications, New Series Vol 19. München: K.G. Saur.

Lassila, Ora. 1998. Web Metadata: A Matter of Semantics. IEEE Internet Computing, 2(4): 30-37.

Library of Congress. 2012. Bibliographic Framework as a Web of Data: Linked data Model and Supporting Services. Washington, DC: Library of Congress. Available at: https://www.loc.gov/bibframe/pdf/marcld-report-11-21-2012.pdf

Library of Congress. 2016. Overview of the BIBFRAME 2.0 Model. Available at: https://www.loc.gov/bibframe/docs/bibframe2-model.html.

López, Pedro López. 1996. Introducción a la Bibliometría. Valencia: Promolibro.

Library of Congress. n.d. What's New in BIBFRAME 2.0. Available at: https://www.loc.gov/bibframe/docs/bibframe2-whatsnew.html

MacCallum, Sally. 2016. BIBFRAME and Linked Data for Libraries. In Linked Data for Cultural Heritage, ed. Ed Jones \& Michele Seikel. Chicago: ALA Editions, 105-123.

Miller, Eric. 1998. An Introduction to the Resource Description Framework. D-Lib Magazine, May 1998. Available at: http://www.dlib.org/dlib/may98/miller/05miller.html

Mitchell, Eric. 2013. Library Linked Data: Research and Adoption. Library Technology Reports, 49, 5. Chicago: ALA Techsource.

Library of Congress. n.d. b. BIBFRAME 2.0 Vocabulary List View. Available at: http://id.loc.gov/ontologies/bibframe.html

Munford, W.A. 1987. Who Was Who in British Librarianship, 1800-1985. London: Library Association.

Obituary. 1954. Library Association Record, 56(12): 500.

Obituaries. 1953. Transactions of the Newcomen Society, 29: 273-279. [Published 1955]

Olding, R.K. 1966. Readings in Library Cataloguing. Contributions to Library Literature, 6. Hamden,

CT: Archon Books.

Olding, R.K. 1968. Wyndham Hulme's Literary Warrant \& Information Indication. Los Angeles: University of California, Graduate School of Library Service.

Petek, Marija. 2004. Bibliografski odnosi v knjižničnem katalogu. Knjižnica, 48: 39-55.

Pritchard, Alan. 1969. Statistical Bibliography or Bibliometrics? Journal of Documentation, 25(4), 348-349.

Richardson, Ernest Cushing. 1901. Classification: Theoretical and Practical. New York: Charles Scribner's Sons.

Rodriguez, Robert D. 1984. Hulme's Concept of Literary Warrant. Cataloging \& Classification Quarterly, 5(1): 17-26.

Sayers, W. C. Berwick. 1926. A Manual of Classification for Librarians \& Bibliographers. London: Grafton \& Co.

Shaw, Mary Keen. 2017. Cataloging Library Resources: An Introduction. Lanham: Rowman \& Littlefield. 
Thomas Dousa. 2017. E. Wyndham Hulme's Classification of the Attributes of Books: On an Early Model of a Core Bibliographical Entity.

NASKO, Vol. 6. pp. 21-38.

18

Smiraglia, Richard. 2001. The Nature of "A Work": Implications for the Organization of Knowledge. Lanham, MD \& London: The Scarecrow Press, Inc.

Souček, Jiří, Souček, Martin, \& Drobíková, Barbora. 2013. Konceptuální model informace a FRBR. ProInflow: Časopis pro informační vědy, 5, Speciální čislo 2013: 122-134. Available at: http://www.phil.muni.cz/journals/index.php/proinflow/article/view/731/825

Stokes, Roy R. 2003. Bibliography. In Encyclopedia of Library and Information Science, Second Edition. Volume 1, ed. Miriam A. Drake. New York/Basel: Marcel Dekker, Inc., 280-287.

Stuart, David. 2016. Practical Ontologies for Information Professionals. Chicago: Neal-Schuman.

Svenonius, Elaine. 2000. The Intellectual Foundation of Information Organization. Cambridge, Massachusetts \& London, England: The MIT Press.

Weston, David. 2010. Ferguson, John. In Oxford Dictionary of National Biography, Volume 19: Fane-Flatman, ed. H.C.G. Matthew \& Brian Harrison. Oxford: Oxford University Press, 359360.

Wuellner, Bernard. 2012. Dictionary of Scholastic Philosophy. Fitzwilliam, New Hampshire: Loreto Publications. [Originally published: Milwaukee: The Bruce Publishing Company, 1956] 